Article

\title{
Engineering Women's Attitudes and Goals in Choosing Disciplines with Above and Below Average Female Representation
}

\author{
Dina Verdín ${ }^{1, *}$, Allison Godwin ${ }^{1}{ }^{(1)}$, Adam Kirn ${ }^{2}$, Lisa Benson ${ }^{3}$ and Geoff Potvin ${ }^{4}$ \\ 1 School of Engineering Education, Purdue University, West Lafayette, IN 47907, USA; godwina@purdue.edu \\ 2 Colleges of Engineering and Education, University of Nevada, Reno, NV 89557, USA; akirn@unr.edu \\ 3 Department of Engineering and Science Education, Clemson University, Clemson, SC 29634, USA; \\ lbenson@clemson.edu \\ 4 Department of Physics \& STEM Transformation Institute, Florida International University, Miami, \\ FL 33199, USA; gpotvin@fiu.edu \\ * Correspondence: dverdin@purdue.edu
}

Received: 15 December 2017; Accepted: 5 March 2018; Published: 13 March 2018

\begin{abstract}
Women's participation in engineering remains well below that of men at all degree levels. However, despite the low enrollment of women in engineering as a whole, some engineering disciplines report above average female enrollment. We used multiple linear regression to examine the attitudes, beliefs, career outcome expectations, and career choice of first-year female engineering students enrolled in below average, average, and above average female representation disciplines in engineering. Our work begins to understand how the socially constructed masculine cultural norms of engineering may attract women differentially into specific engineering disciplines. This study used future time perspective, psychological personality traits, grit, various measures of STEM identities, and items related to career outcome expectations as theoretical frameworks. The results of this study indicate that women who are interested in engineering disciplines with different representations of women (i.e., more or less male-dominated) have significantly different attitudes and beliefs, career goals, and career plans. This study provides information about the perceptions that women may have and attitudes that they bring with them into particular engineering pathways.
\end{abstract}

Keywords: engineering disciplinary differences; masculine social norms; women in engineering

\section{Introduction}

To progress as a nation, maintaining an economy that thrives from productivity, creativity, and entrepreneurship and to preserve the scientific and engineering leadership "the United States must aggressively pursue the innovative capacity of all of its people (National Academies Committee on Science, Engineering and Public Policy 2007, p. 3; President's Council of Advisors on Science and Technology 2012). Since the 1990s, women have earned nearly $57 \%$ of all bachelor's degrees; however, participation in certain fields, i.e., engineering, has remained low compared to men (National Center for Education Statistics 2015). While there has been a steady increase in the number of women participating in engineering fields in the past 20 years, "women's participation remains well below that of men at all degree levels and in all fine fields of engineering" (National Center for Education Statistics 2015, p. 6).

In the past two decades, the percentage of women earning bachelor's degrees in engineering has not dramatically changed; this number has remained around 20\% (Yoder 2015). However, the representation of women among specific engineering disciplines varies from almost parity (49.7\% women in environmental engineering) to percentages well under the national average 
(10.0\% women in construction management engineering; (Yoder 2015)). In this paper, we extend previous results by focusing on how women's attitudes may attract women differentially to specific engineering disciplines. By treating engineering not as a monolith, but as a field with multiple disciplines, we can better understand the characteristics of women who are drawn to engineering disciplines with higher and lower representation of women. Understanding the types of women who may choose more or less male-dominated engineering disciplines may provide ways to attract and retain more women into the engineering profession and address the significant concern of gender representation.

\subsection{Cultural Norms of Engineering}

Engineering has historically been highlighted as a male dominated field, whereas women in the engineering field have been perceived as invaders (Bix 2004; Slaton 2015). Masculinity as a dominating feature of engineering has been documented in numerous publications. This norm of engineering is socially constructed and communicated by the dominant group, namely men. Some norms are explicit and easy to identify, while others are more implicit (Cialdini and Trost 1998). Social norm theory has been extensively used in psychology, behavioral health, and counseling to explain the efficacy of perceptions (or misperceptions) about the behavior of individuals in social settings (Perkins and Berkowitz 1986). We use social norm theory to understand how women who choose engineering disciplines with above and below average female representation may have different characteristics explained by the disciplinary differences in engineering.

Social norms have been characterized as both personality and cognitive traits (Cejka and Eagly 1999), and a summary of these traits is shown in Table 1. An examination of the dimensions, masculine personality and masculine cognitive, revealed that individuals believed that both masculine personality and cognitive attributes were most important for success in male-dominated occupations, like engineering. Raters also perceived male-dominated occupations to have higher earning potentials and to be more prestigious than other occupations. Whether these perceptions are true or not, the perception of occupations may be more important to how students, especially women, choose male-dominated disciplines in their respective university.

Table 1. Description of Masculine Dimensions (Cejka and Eagly 1999).

\begin{tabular}{cc}
\hline Dimension & Attributes \\
\hline Competitive \\
Daring \\
Unexcitable \\
Dominant \\
Adventurous \\
Stands up under pressure \\
Aggressive \\
Courageous \\
\hline Analytical \\
Masculine Cognitive & Mathematical \\
& Good with numbers \\
& Exact \\
& Good at reasoning \\
& Good at abstractions \\
Good at problem solving \\
Quantitatively skilled
\end{tabular}

Engineering is a prototypical example of a male-dominated discipline that conforms to social norms of masculinity (Akpanudo et al. 2017). Engineering has been historically framed as a profession that excluded the participation of women, promoted dominant images of masculinity to attract men into the profession, and became an occupation well suited for "proving manhood" (Frehill 2004, p. 2). 
Further evidence that the culture of engineering reinforces masculinity is seen when referring to mathematics as a "hard" skill and interpersonal skills as "soft." "Hard" skills are "connected to intellectual rigor as well as masculinity and virility, while "soft" skills are less important, and related to weakness and impotence" (de Pillis and de Pillis 2008, p. 36). This construction of engineering as for men has persisted in the culture of engineering classrooms (Faulkner 2000, 2007; Tonso 2006) and workplaces (Collinson 1998; Faulkner 2009) to date. Compared to other STEM disciplines that have reached gender parity, including biology, chemistry, and mathematics, engineering trails woefully behind with only $20 \%$ of bachelor's degrees awarded to women. This statistic has remained stagnant for the past two decades (Snyder et al. 2016).

\subsection{Climate of Engineering}

Many studies have documented the various factors that contribute to the low representation of women in engineering. For example, the climate of engineering programs, shaped by social norms, often affects students' perceptions of inclusivity and feelings of being supported and accepted. Several studies have found that women were more likely to feel a lack of belonging than men (Seymour and Hewitt 1997; Geisinger and Raman 2013; Camacho et al. 2010; Smith et al. 2012). The ethnographic work of Tonso (2007) revealed the identity ascribed to engineering students, on campus, "served as a constant reminder of who belonged and who did not" (p. 250). In her study, students' mechanisms of belonging emerged in the form of labels used to identify engineers as 'Nerds' (design engineers), 'Academic Achievers' (best performance in core curriculum concepts), and 'Greeks' (social-achievers, concerned more with campus activities), women, despite performing well in their classes were often only recognized as Greeks, whereas "women student engineers who should have belonged among the Nerds became identified as [just] women" (Tonso 2007, p. 254). Being "highly visible as women yet invisible as engineers" is described by Faulkner (2013) as the in/visibility paradox (p. 172), which serves to highlight women as other in this male-dominated discipline.

Studies have typically focused on women's perceptions of engineering, treating engineering as a monolith rather than understanding the climate among the different disciplines. In most work focusing on engineering there is often an implicit assumption that the climate of engineering is homogenous among all disciplines. While few studies focus on understanding the climate of each individual engineering disciplines for women, a study by Brawner et al. (2012) sought to understand why women were more drawn to industrial engineering over other engineering majors. Brawner and colleagues found that the resources afforded to women in industrial engineering programs were "warmth of the faculty, sociability within the department, and good job prospects ... the major is inviting and the coursework provides flexibility" (Brawner et al. 2012, p. 312). Similarly, another study by Foor and Walden (2009) found that the popular narrative around industrial engineering positions this discipline as having feminine qualities and thus "legitimizes [industrial engineering] as an appropriate and gender-authentic place for women to occupy" (p. 47). In an earlier study, Godfrey (2007) affirmed that engineering disciplines with a higher female representation subsequently helped develop an engineering culture that attracts more women. Other studies looking at gender differences in engineering found that women often positioned themselves as non-feminine and were reluctant to position their experiences as women in predominantly male fields (Jorgenson 2002). Jorgenson (2002) found that some women were eager to separate themselves from "ordinary" women, believing engineering is a "gender-neutral territory," and were in opposition to women in engineering organizations. These accounts of dismissing or rejecting female identities were "strategies widely observed among female scientists and engineers to disqualify their femininity by muting their visibility as women" (Jorgenson 2002, p. 370). The behaviors women engineers adopt of downplaying their gender identity is consistent with other studies related to gender and engineering identity (Du 2006; Phipps 2002). Henwood (1996) reiterates that the problem of engineering and "other areas defined as 'men's work' [e.g., physics] need[s] to be understood within a much broader context of gender and work which examines how gender is constructed through work and by what mechanisms gender 
inequality is maintained" (p. 212). In this paper, we examine women's attitudes across engineering disciplines to understand how the perceptions and social norms within engineering disciplines may attract women differentially and begin to explain the major female enrollment discrepancies among different engineering fields.

\section{Project Overview}

We hypothesize that the experiences of women in engineering are not the same across all engineering disciplines. Despite the low enrollment of women in engineering as a whole, some engineering disciplines report above average female enrollment. For example, environmental, biomedical, agriculture and biological, chemical, and industrial engineering award $49.7 \%, 40.9 \%$, $34.4 \%, 32.4 \%$, and $29.7 \%$ of bachelor's degrees to women, respectively. Other engineering disciplines, such as electrical $(12.5 \%)$, mechanical $(13.2 \%)$, and aerospace $(14.2 \%)$ engineering lag behind the overall average (19.9\%) (Yoder 2015). We acknowledge that all of these percentages are well under the number of women enrolling in higher education nationally, thus classifying engineering overall as male-dominated (Snyder et al. 2016).

Despite the problem of underrepresentation of females in engineering, differences by gender in terms of disciplinary degree enrollment is an understudied phenomenon. Some studies have examined disciplinary differences (Ben-Shem and Avi-Itzhak 1991; Izraeli et al. 1979; Potvin et al. 2013; Godwin and Potvin 2013) or gender differences within particular disciplines (Godwin et al. 2018; Lord et al. 2011), but few systematically examine gender differences by engineering discipline (see Hartman and Hartman 2009). Engineering, most often, is treated as a monolith. This study is unique in examining engineering disciplinary differences using various attitudinal constructs, career outcome expectations, and career aspirations. Also unique to this manuscript is in characterizing the varying degrees of female representation in engineering disciplines as below average, average, and above average representation with respect to the $19 \%$ overall national average of female enrollment in engineering.

\section{Research Questions}

Our work examines attitudes and beliefs of first-year, undergraduate female engineering students who are interested in degree pathways in below average, average, and above average female representation disciplines in engineering. This study begins to understand how masculine attitudes may attract more or less women into particular engineering fields. Our participants have not yet been fully immersed in their chosen engineering disciplines, thus their incoming attitudes and beliefs are not yet shaped by their participation in engineering culture. This study is an initial examination of the differences that exist among women who have not yet transitioned out of general first-year engineering programs into their respective engineering disciplines.

RQ1. What are the differences in attitudes and beliefs for first-year, undergraduate women in engineering disciplines that have above average, average, and below average female representation?

RQ2. What are differences in career outcome expectations for first-year, undergraduate women in engineering disciplines that have above average, average, and below average female representation?

RQ3. What are differences in career aspirations for first-year, undergraduate women in engineering disciplines that have above average, average, and below average female representation?

We hypothesize that women in the above average female representation group will have significantly different and more traditionally feminine attitudes, beliefs, career outcome expectations, and career aspirations than their peers (e.g., higher agreeableness, a personality trait; stronger desire to help others, a career outcome expectation; and a higher interest in careers in health or non-profit sectors, a career aspiration). Conversely, we hypothesize that women in the below-average female representation group will have significantly different and more traditionally masculine attitudes, 
beliefs, career outcome expectations, and career aspirations than their peers (e.g., higher physics and engineering identities; stronger desire for making money, a career outcome expectation; and more interest in entrepreneurship or engineering industry as career aspirations). Lastly, we hypothesize that women in the average female representation group will have a mixture of feminine and masculine attitudes, beliefs, career outcome expectations, and career aspirations. For example, we hypothesize that women in the average female representation group will be equally likely to have career outcome expectations of making money and helping others.

\section{Theoretical Frameworks}

The theoretical frameworks used in this study consist of future time perspective (a motivation framework modified for use in engineering), "Big 5" psychological personality traits (i.e., extraversion, agreeableness, conscientiousness, neuroticism, and openness), grit, various measures of STEM identities, and items related to career outcome expectations. Each of these frameworks have a rich, often unconnected history in education, psychology, and engineering education studies. Below, we discuss each of these frameworks separately to provide a picture of how they have been operationalized in prior literature and in this study.

\subsection{Future Time Perspective}

Future time perspective (FTP) relates to an individuals' perception of time as a psychological phenomenon, where time perspective "considers the present situation, includes the future, present and also the past" which leads to a "motivational goal-setting processes" (Husman and Lens 1999, p. 114). FTP consists of three dimensions (1) time orientation, orientation towards the past or future, (2) instrumentality, perceptions of the usefulness of a task in relation to their desired future or goals, and (3) perception of time, an individuals' view that time can help improve or make things better (Husman and Lens 1999; Husman and Shell 2008; Kirn and Benson 2018). A study of engineering students found that those who had a more positive outlook on their long-term goals were more likely to persist in engineering and problem-solving tasks (Benson et al. 2017; Kirn and Benson 2018). Husman and Lens (1999) found that students whose time orientation is placed more towards the future are more likely to continue working on tasks than students who are more oriented towards the present.

\subsection{Psychological Personality Traits}

The Big Five taxonomy of personality traits of extraversion, agreeableness, conscientiousness, neuroticism, and openness are considered a "common human structure of personality" (McCrae and Costa 1997, p. 515). Scholars have used the Big Five taxonomy to understand academic motivation, academic achievement, and goal orientation (Komarraju et al. 2011; Komarraju et al. 2009; Sorić et al. 2017; Ross et al. 2003). For this study, we will focus only on two personality traits, agreeableness and conscientiousness, as they were found to be significant in differentiating between attitudinal characteristics of engineering students (Kirn et al. 2016). Agreeableness is a personality trait that describes an individual's interpersonal relationship with others. Agreeableness is strongly connected to empathy and volunteering to help others, and is positively related to cooperativeness, among other traits (Graziano and Tobin 2009). Conscientiousness is defined as "individual differences in the propensity to follow socially prescribed norms ... to be goal directed, to plan, and to be able to delay gratification" (Roberts et al. 2009, p. 369). Both conscientiousness and agreeableness have been found to be positively linked to mastery-approach goals (McCabe et al. 2013), where an individual with mastery-approach is more likely to be intrinsically motivated to learn, believes competence can develop over time, and uses learning strategies that foster comprehension (Elliot and McGregor 2001). In a meta-analysis, conscientiousness was found to be a significant positive predictor of job performance, academic performance, and academic retention, whereas agreeableness was not a significant predictor (Trapmann et al. 2007). 


\subsection{Grit}

Grit is defined as the perseverance and passion for long-term goals, research studies have found that this personality trait predicts success over and beyond mental abilities, through grade point average and scholastic aptitude test (SAT) scores, and conscientiousness (Duckworth et al. 2007). An individual is said to possess grit when they "work strenuously towards challenges, maintaining effort and interest over years despite failure, adversity, and plateaus in progress" (Duckworth et al. 2007, p. 1087). Duckworth et al. (2007) (Duckworth and Quinn 2009) found that gritty individuals have higher levels of education, had fewer career changes, and earned a higher GPA (despite having lower SAT scores) than their less gritty counterparts. In a study of West Point Cadets, grit was found to be a better predictor of first summer retention than measures of compared to a Whole Candidate Score, where this score consists of "weighted composite of high school rank, SAT score, participation in extracurricular activities and a standardized physical exercise evaluation" (Duckworth and Quinn 2009, pp. 170-71). Another study of first-year engineering students showed that women had higher measures of grit when compared to men (Jaeger et al. 2010). Similarly, another study focused on first-year engineering students found that perseverance of effort, a construct within grit, was a significant predictor of one- and two-year engineering retention, while controlling for overall grade in mathematics (Choi et al. 2017). Challenging the perception that grit is a stand-alone trait, i.e., some students have it while others do not, a study by Verdín et al. (2018) found that grit can be fostered by seeing oneself as an engineer and feeling as though one belongs in engineering.

\subsection{STEM Identities}

Learning is a "process of coming to be, of forging identities in activity in the world. In short, learners are never only that, but are becoming certain sorts of subjects with certain ways of participating in the world" (Lave 1992, p. 3). As students participate in their STEM classes, they are enacting identities or ways of being in the science and/or engineering community. Identity, in the education literature, has been defined as "being recognized as a certain 'kind of person,' in a given context" (Gee 2001, p. 99). Borrowing from the work of Gee (2001) scholars in science education (Johnson et al. 2011; Carlone and Johnson 2007; Brickhouse et al. 2000), physics education (Potvin and Hazari 2013; Hazari et al. 2010), and engineering education (Godwin 2016; Godwin et al. 2016) used his notion of identity to create measures of subject-related role identities. Subject-related role identity entails "the authoring of one's self" within the engineering, physics, and/or mathematics context and is a process that is "continually evolving [and] self-reflexive" (Godwin et al. 2016, p. 314). An individual cannot be recognized as a certain kind of person unless he/she makes visible (performs) their competence in STEM domains (Carlone and Johnson 2007). The authoring of one's self within the engineering, physics, and mathematics context is done through three interrelated constructs: interest, recognition, and performance/competence. Where interest is the desire to learn and understand STEM content, recognition entails seeing oneself and being seen by others as the kind of person that can do STEM, and performance/competence is the belief in one's ability to perform required STEM tasks or processes (Hazari et al. 2010). In this study, the term "STEM identities" is used to holistically represent mathematics identity, physics identity, and engineering identity. Prior modeling work has proven that the use of interest, recognition, and performance/competence constructs validly measure mathematics (Cribbs et al. 2015), physics (Potvin and Hazari 2013), and engineering identities (Godwin et al. 2013; Godwin 2016) for first-year university students and first-year engineering students, specifically.

\subsection{Career Outcome Expectations}

Bandura (1986) stated that "outcome expectations are derived from observed or experienced consequences and may provide a source of motivation for observational learning" (p. 76). Career outcome expectations stem from social career theory. They are beliefs regarding the results of various courses of action (Lent et al. 2003). They reflect future outcomes that students desire for a particular 
career choice (Lent et al. 2000). Social cognitive theory posits that outcome expectations, mediated by self-efficacy, affect interest (Lent et al. 1994, 2002). To explain how students make career-related decisions, Lent et al. $(1994,2002)$ connected Bandura's theory of self-efficacy and outcome expectations to interest, goals, and actions. In this work, we use career outcome expectations that have been shown to be particularly important for engineers (Potvin et al. 2013; Verdín and Godwin 2018).

\section{Methods}

The data used in this analysis were collected in Fall 2015 at four public institutions in different regions of the United States. This study was part of a larger mixed methods project (Kirn et al. 2016; Benson et al. 2017). The target population was first-year engineering students, who were invited to complete a survey during the first two weeks of classes. The survey was administered via paper format to ensure high response rates, and responses were digitized for further analysis. The survey consisted of multiple survey items used to measure students' attitudinal profiles including belongingness in engineering, STEM identities (i.e., engineering, physics, and mathematics), "Big 5" personality traits, motivation, and career interest, and demographic information as well as students' career goals and choice of engineering major. We asked students to indicate their interest in a comprehensive list of engineering degrees.

From the overall student participants $(n=2916), 70 \%\left(n_{M}=2028\right)$ identified as male, $23 \%\left(n_{\mathrm{F}}=675\right)$ identified as female, and $7 \%\left(n_{\mathrm{D}}=213\right)$ identified as a gender different from female or male. This study focuses on the different attitudes, beliefs, and motivation among females interested in various engineering disciplines; thus, the male students and students who identified with non-binary genders removed from this analysis. The distribution of female participants from each institution is as follows: Southwestern land grant $n=82(12 \%)$, Southern land grant $n=278(41 \%)$, Midwestern land grant $n=240$ (36\%), and Hispanic Serving Institution $n=75(11 \%)$. The race/ethnicity breakdown is $13 \%$ Asian, 6\% African American/Black, 10\% Hispanic or Latina, 1\% Native American or Alaska Native, 0.2\% Native Hawaiian or other Pacific Islander, $0.8 \%$ Middle Eastern, 9\% multiple race/ethnicities, $58 \%$ white, and $2 \%$ another race besides the listed choices (e.g., write in response).

The female representation of engineering disciplines (i.e., below average, average, and above average representation) was determined using Yoder (2015) Engineering by Numbers report, which gives the percentage of women awarded bachelor's degrees in each discipline on a yearly basis. Construction management engineering is the only discipline not reported in the Yoder (2015) report, thus the percentage of women in this field was found through the Bureau of Labor Statistics (2018). We split the data into thirds using the tercile cutoffs based on percentage of female enrollment in the engineering discipline. The lower tercile indicated below average representation of female engineers, middle tercile indicated average representation of female engineers, and upper tercile indicated above average representation of female engineers. Figure 1 depicts the engineering disciplines along with the percentage of female representation and the tercile divisions where the three groups were formed. The disciplines have been abbreviated according to the legend in Table 2.

Table 2. Breakdown of Representation of Women in Engineering in the Sample.

\begin{tabular}{lll}
\hline Below Average & Average & Above Average \\
\hline Construction & Nuclear Engineering & Industrial Engineering \\
Management Engineering & Computer Engineering & Chemical Engineering \\
Electrical Engineering & Engineering Physics & Biological and Agricultural \\
Mechanical Engineering & Other Engineering & Engineering \\
Aerospace Engineering & Civil engineering & Biomedical Engineering \\
Information Technology & Materials Engineering & Environmental Engineering \\
\hline$n=221$ & $n=235$ & $n=425$
\end{tabular}

Note: Participants were allowed to select multiple disciplines of interest; group sizes do not reflect the overall women sample size. 


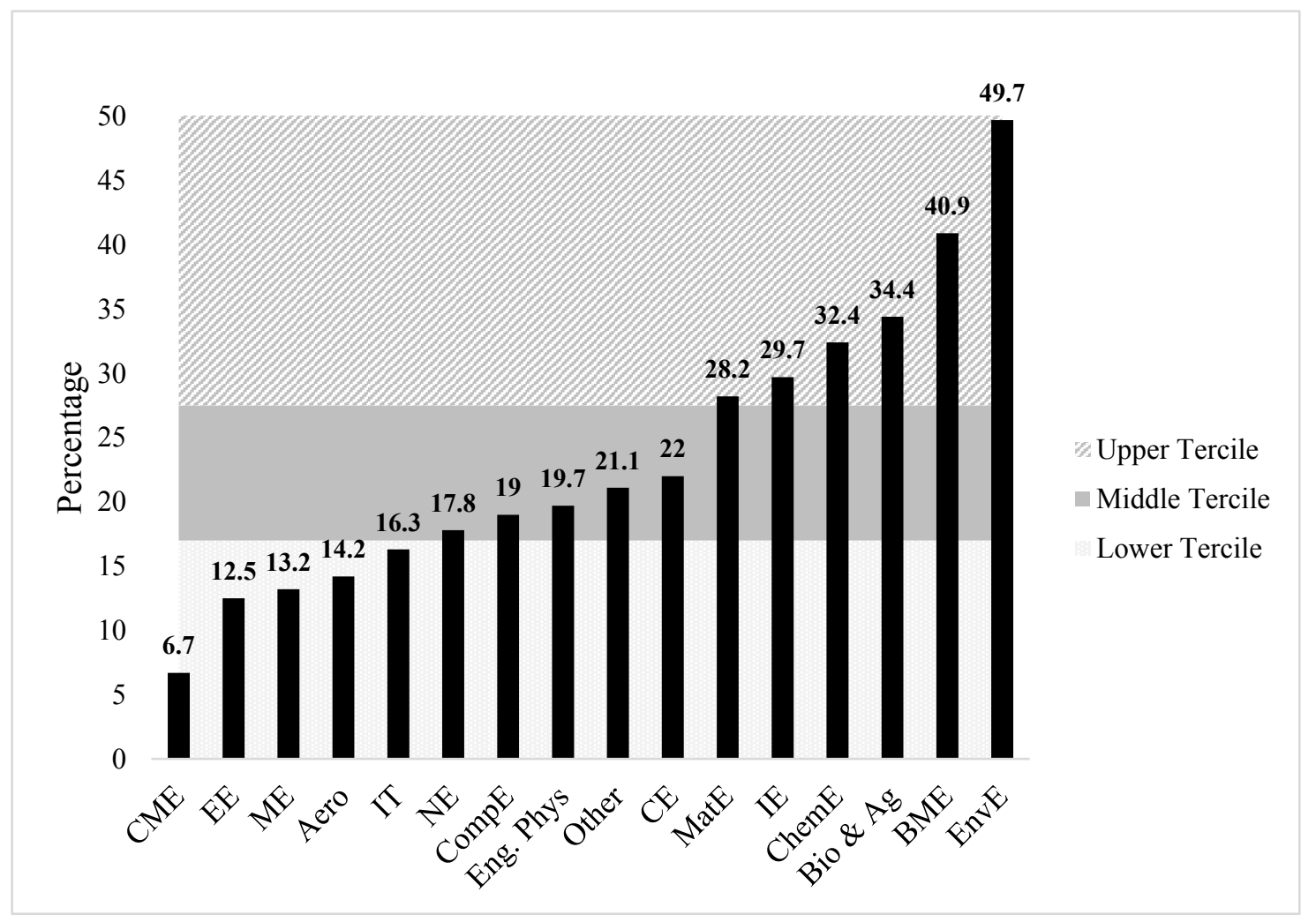

Figure 1. Percentage of Women in Engineering Disciplines in the 2014-2015 Academic Year (Yoder 2015). Abbreviations are as follows: $\mathrm{CME}=$ Construction Management Engineering, $\mathrm{EE}=$ Electrical Engineering, Aero = Aerospace $/$ Aeronautical Engineering; IT = Information Technology; NE = Nuclear Engineering, CompE = Computer Engineering; Eng. Phys. = Engineering Physics; $\mathrm{CE}=$ Civil Engineering, MatE = Materials Engineering, IE = Industrial Engineering; ChemE = Chemical Engineering, Bio \& Ag = Biological and Agricultural Engineering; $\mathrm{BME}=$ Biomedical Engineering; EnvE = Environmental Engineering.

After selecting which disciplines were considered below average, average, or above average female representation, we used this categorization to drive how we grouped our participants. The below average, average, and above average female representation groups were created using participants' indicated level of interest for each engineering discipline, which are listed in Table 2 with abbreviations. Level of interest was rated using a seven-point anchored numeric scale of $0=$ "Not at all interested" to $6=$ "Extremely interested." Participants who rated having an interest in construction management engineering, electrical engineering, mechanical engineering, and aerospace engineering, and information technology greater than or equal to 4 and did not indicate greater interest in other disciplines were grouped as below average female representation. Participants who rated having an interest in nuclear engineering, computer engineering, engineering physics, other engineering, civil engineering, and materials engineering greater than or equal to 4 and did not indicate greater interest in other disciplines were grouped as average female representation. Lastly, participants who indicated having an interest in industrial engineering, chemical engineering, biological and agricultural engineering, biomedical engineering, and environmental engineering greater than or equal to 4 and did not indicate greater interest in other disciplines were grouped as above average female representation.

Participants may belong to one or more group given that students were free to choose any and all engineering disciplines that interested them. This method was chosen to account for the fact that three out of the four institutions had a general first-year engineering program in which all students enroll in common classes. The Hispanic Serving Institution in our sample did not have a common first-year engineering program, thus $11 \%$ of our sample size had declared majors. A first-year engineering 
program admits all students to engineering in general rather than a specific discipline. Students still entered each university with disciplines of particular interest, which can be simultaneously compared in our methodological approach (as described below). Our approach to categorizing student interest by degree pathway has been used in prior studies of student pathways (Godwin et al. 2016, 2018; Godwin et al. 2013; Cass et al. 2011). The distribution of female participants per grouping is as follows: $221(33 \%)$ participants for below average female representation, $235(35 \%)$ for average female representation, and $425(62 \%)$ for above average female representation. Table 2 outlines which engineering disciplines fall into the terciles of below average, average, and above average female representation in engineering disciplines and the sample sizes of women in these disciplines.

To answer the research questions, separate multiple linear regressions were used to examine how women's attitudes, career outcome expectations, and career aspirations were predicted by being in a below average, average, and above average female representation group. The method of analysis was selected to understand the relationship between the outcome variables (i.e., attitudes, beliefs, career outcome expectation, and career aspirations) among engineering disciplines that have above-average, average, and below-average female representation. The choice of multiple regression allowed us to control for membership in each group while estimating the effect of each group membership on the attitudinal outcomes. A composite score for each construct was calculated by averaging each student's response for all individual predictor variables in this analysis. Statistical analyses were conducted in the R programming language and statistical software system version 3.4.3 (R Core Team 2017).

\subsection{Measurement Instruments}

Below, we describe the different survey constructs used to measure the theoretical frameworks explored in this study.

\subsubsection{Future Time Perspective}

Future Time Perspective was measured as five latent constructs: expectancy (belief one will do well in their courses, five items); connectedness (tying current tasks to future goals, four items); instrumentality (current tasks are useful for my emerging identity as an engineer, three items); value (value of future goals over present goals, three items); and perceptions of future (domain specific valuing of the future, four items). These items also demonstrated strong validity evidence across face, content, and construct validity (Kirn and Benson 2018; Shell and Husman 2008). Students were asked to respond to questions relating to their attitudes and beliefs about their experiences in their respective first-year engineering courses, engineering major, and future using a rating score of 0 (Strongly disagree) to 6 (Strongly agree). The Cronbach alpha estimates for the measures that were significant in our study were $\alpha=0.77$ for instrumentality and $\alpha=0.86$ for perceptions of future, indicating good construct reliability (see Tavakol and Dennick 2011).

\subsubsection{Psychological Personality Traits}

A reduced version of the Goldberg (1992) 50-item IPIP Big-Five personality factor was selected for this study. Only 25 most reliable items were used from the Goldberg (1992) IPIP Big-Five personality inventory. The personality factors refer to neuroticism, extraversion, openness to experience, agreeableness, and conscientiousness; each of these factors had five items. Students were asked to rate how accurately phrases pertaining to the personality traits described them as on a scale of 0 (Very inaccurately) to 6 (Very accurately). The Cronbach alpha estimate for the measures that were significant in our study were $\alpha=0.80$ for agreeableness and $\alpha=0.61$ for conscientiousness, indicating reliability.

\subsubsection{Grit}

The instrument for grit: persistence of effort and consistency of interest was borrowed from Duckworth et al. (2007). Students were asked to rate, on a scale of 0 (Not at all like me) to 6 (Very much 
like me) how closely the items described them. The Cronbach alpha estimates were $\alpha=0.68$ for grit: persistence of effort, and $\alpha=0.79$ for grit: consistency of interest, indicating reliability.

\subsubsection{STEM Identities}

The instrument for mathematics and physics identity was borrowed from the SaGE Survey (2011) and the instrument for engineering identity was borrowed from Godwin (2016). Students were asked to rate, on a scale of 0 (Strongly disagree) to 6 (Strongly agree) the extent to which they agree or disagree with statements about their interest, recognition, and performance/competence beliefs in mathematics, physics and engineering. The Cronbach alpha estimates for the measures that were significant in our study were $\alpha=0.89$ for engineering interest, $\alpha=0.90$ for engineering performance/competence, $\alpha=0.89$ for physics interest, $\alpha=0.90$ for physics recognition, $\alpha=0.92$ for physics performance/competence, and $\alpha=0.91$ for mathematics performance/competence. Composite scores were created for engineering, physics, and mathematics identity using the three constructs, with Cronbach alpha values of $\alpha=0.90$ for engineering identity, $\alpha=0.90$ for physics identity and $\alpha=0.94$ for mathematics identity.

\subsubsection{Career Outcome Expectations}

The career-related outcome expectation items used in this analysis are borrowed from Lent et al. (2003) and Potvin et al. (2013). Using a scale of 0 (Not at all) to 6 (Very much so), participants were asked to rate how important the following factors were for their future career satisfaction: making money, becoming well known, helping others, supervising others, working with people, inventing/designing things, and developing new knowledge and skills. These items did not have a factor structure; thus, each item was investigated separately and no construct reliability measures (Cronbach alpha values) are reported.

\subsubsection{Career Aspirations}

The career aspirations list was developed by the research team based on common career pathways after graduation for engineers. Using a scale of 0 (Not at all likely) to 6 (Extremely likely), participants were asked to rate the currently likelihood of choosing a career in the following fields: academia (higher education), engineering (industry), entrepreneurship/start a company, government/policy, K-12 education, law, medicine/health, non-profit/non-government organization, and other. These items are similar to the career outcome expectations in that they do not have a factor structure. Each item was investigated separately, and no construct reliability measures are reported.

\section{Results}

First, assumptions of outliers, univariate and multivariate normality, and multicollinearity were examined. Data were then examined for multivariate outliers using Mahalanobis distance. Based on these metrics, 43 cases were removed from the analysis. Univariate normality was found to be within acceptable range of skewness (within an absolute value of less than 2.0) and kurtosis (absolute value of less than 7.0; (Muthen and Kaplan 1992; Curran et al. 1996)). Multivariate normality did not hold; however, using ordinary least squares is sufficient for non-normality distributed data. The correlation matrix of all predictor variables was examined to test for multicollinearity, analysis revealed no variables were highly correlated, i.e., above 0.80 . Similarly, the variance inflation factor (VIF) and tolerance statistic was examined for indication of multicollinearity. VIF indicates whether there is a high linear relationship with other predictor variables; Menard (1995) suggests values above 5 are cause for concern. Tolerance statistic is the reciprocal of the VIF; Menard (1995) suggest values below 0.20 are cause for concern. The VIF values of all regression models ranged from 1.07 to 1.94 . Tolerance statistics ranged from 0.82 to 0.96 . The collinearity statistics and diagnostics indicate no concern for multicollinearity. We then tested the construct reliability of all the latent variables used in this analysis. Only the measures that were significant in the analysis are reported. All measures used in this study had construct reliability within the 0.70 to 0.95 range, indicating that the items are in fact closely related 
(Tavakol and Dennick 2011). The mean, standard deviation, and correlation matrix can be found online for all variables used in this analysis (Supplementary Materials).

We then used multiple regressions to predict differences in women's attitudes, beliefs, and career goals based on membership the below average, average, and above average female representation groups. Results for attitudes and beliefs are shown in Table 3, results for career outcome expectations are shown in Table 4, and results for career aspirations are shown in Table 5.

\subsection{Attitudinal Outcomes}

We found results that are consistent with our hypotheses. Women in the below average female representation group were significantly higher in self-reported measures closely related to masculine social norms i.e., engineering identity $(\beta=0.12, p<0.01)$, engineering interest $(\beta=0.17, p<0.001)$, engineering performance/competence $(\beta=0.11, p<0.05)$, physics identity $(\beta=0.17, p<0.001)$, interest in physics $(\beta=0.19, p<0.001)$, feeling recognized as a physics person $(\beta=0.13, p<0.01)$, and physics performance/competence $(\beta=0.12, p<0.01)$.

Women in the above average female representation group demonstrated less stereotypical masculine norms in that they were less likely to identify as a physics person $(\beta=-0.09, p<0.05)$, and feel recognized by others as a physics person $(\beta=-0.09, p<0.01)$. Similarly, women in the above average female representation group were significantly higher in a personality trait that are categorized as more feminine, agreeableness $(\beta=0.18, p<0.001)$.

Grit may be a gender-neutral personality trait as both women in the below average and above average female representation groups demonstrated significantly high measures of grit: persistence of effort $(\beta=0.11, p<0.01)$ and $(\beta=0.09, p<0.05)$, respectively.

Table 3. Standardized Estimates of Multiple Regression Analysis for Factors for Attitudinal Outcomes.

\begin{tabular}{cccc}
\hline Predictor Variables & $\begin{array}{c}\text { Below Average Female } \\
\text { Representation }\end{array}$ & $\begin{array}{c}\text { Average Female } \\
\text { Representation }\end{array}$ & $\begin{array}{c}\text { Above Average Female } \\
\text { Representation }\end{array}$ \\
\hline Instrumentality & 0.08 & -0.001 & $0.09 *$ \\
Perceptions of Future & $0.12^{* *}$ & -0.02 & -0.02 \\
Agreeableness & 0.05 & -0.03 & $0.18^{* * *}$ \\
Conscientiousness & -0.04 & -0.06 & $-0.10 *$ \\
Grit: Persistence of Effort & $0.11^{* *}$ & -0.02 & $0.09 *$ \\
Grit: Consistency of Interest & $-0.11^{*}$ & -0.02 & -0.04 \\
Engineering Identity & $0.12^{* *}$ & 0.02 & 0.02 \\
Engineering Interest & $0.17^{* * *}$ & 0.01 & 0.01 \\
Physics Identity & $0.11^{*}$ & 0.03 & 0.02 \\
Physics Recognition & $0.17^{* * *}$ & 0.02 & $-0.09 *$ \\
Engineering Performance/Competence & $0.19 * *$ & 0.01 & -0.07 \\
Pathematics Identity & $0.13^{* *}$ & 0.05 & $-0.09 *$ \\
Mathematics Performance/Competence & $0.12^{* *}$ & 0.00 & -0.05 \\
\hline
\end{tabular}

Note. ${ }^{*} p<0.05,{ }^{* *} p<0.01,{ }^{* * *} p<0.001$.

\subsection{Career Outcome Expectations}

In examining factors for future career satisfaction, as hypothesized, women in the below average female representation group demonstrated significantly greater interest in outcomes perceived as masculine traits, i.e., making money $(\beta=0.11, p<0.05)$, becoming well known $(\beta=0.11, p<0.05)$, supervising others $(\beta=0.13, p<0.01)$, and inventing/designing things $(\beta=0.09, p<0.05)$.

We hypothesized that women in the above average female representation group were significantly more interested in careers satisfaction outcomes aligned with feminine traits. Our results confirmed that this group was more interested in helping others $(\beta=0.22, p<0.001)$ and working with people $(\beta=0.11, p<0.05)$ career expectations that are perceived as more feminine. 
Table 4. Standardized Estimates of Multiple Regression Analysis for Factors for Career Outcome Expectations.

\begin{tabular}{cccc}
\hline Predictor Variables & $\begin{array}{c}\text { Below Average Female } \\
\text { Representation }\end{array}$ & $\begin{array}{c}\text { Average Female } \\
\text { Representation }\end{array}$ & $\begin{array}{c}\text { Above Average Female } \\
\text { Representation }\end{array}$ \\
\hline Making money & $0.11^{*}$ & 0.07 & -0.06 \\
Becoming well known & $0.11^{*}$ & -0.03 & 0.01 \\
Helping others & 0.04 & -0.03 & $0.22^{* * *}$ \\
Supervising others & $0.13^{* *}$ & -0.02 & 0.08 \\
Working with people & 0.03 & -0.03 & $0.11^{*}$ \\
Inventing/designing things & $0.09^{*}$ & -0.03 & -0.07 \\
Developing new knowledge and skills & 0.06 & -0.01 & 0.03 \\
\hline
\end{tabular}

Note. ${ }^{*} p<0.05,{ }^{* *} p<0.01,{ }^{* * *} p<0.001$.

\subsection{Career Aspirations}

Lastly, we analyzed career choice for the women in each group. Women in the below average female representation group and average female representation group were more likely to be interested in an engineering industry career, $(\beta=0.08, p<0.05)$ and $(\beta=0.01, p<0.05)$ respectively, and starting a company, $(\beta=0.12, p<0.01)$ and $(\beta=0.10, p<0.05)$ respectively, both career fields perceived as masculine. Women in the below average and average female representation group were significantly less likely to be interested in medicine/health careers $(\beta=-0.15, p<0.001)$ and $(\beta=-0.08, p<0.05)$, respectively. This analysis confirms our hypothesis that women in the average female representation group would have career aspirations that are both masculine and feminine.

Women in the above average female representation group were significantly less likely to be interested in an engineering industry career $(\beta=-0.14, p<0.001)$ and more likely to be interested in a medicine/health career $(\beta=0.12, p<0.01)$, fields that are known to have more women. Women in the above average female representation group were significantly more likely to be interested in a career in nonprofit/non-governmental organization $(\beta=0.16, p<0.001)$.

Table 5. Standardized Estimates of Multiple Regression Analysis for Career Aspirations in the Following.

\begin{tabular}{cccc}
\hline Predictor Variables & $\begin{array}{c}\text { Below Average Female } \\
\text { Representation }\end{array}$ & $\begin{array}{c}\text { Average Female } \\
\text { Representation }\end{array}$ & $\begin{array}{c}\text { Above Average Female } \\
\text { Representation }\end{array}$ \\
\hline Academia (Higher Education) & 0.06 & -0.02 & 0.07 \\
Engineering (Industry) & $0.08^{*}$ & $0.01^{*}$ & $-0.14^{* * *}$ \\
Entrepreneurship/Start a Company & $0.12^{* *}$ & $0.10^{*}$ & -0.04 \\
Government/Policy & 0.04 & 0.05 & 0.02 \\
K-12 Education & -0.03 & $0.10^{*}$ & 0.06 \\
Law & $0.11^{*}$ & 0.04 & $0.13^{* *}$ \\
Medicine/Health & $-0.15^{* * *}$ & $-0.08^{*}$ & $0.35^{* * *}$ \\
Non-profit/Non-government organization & 0.03 & 0.02 & $0.16^{* * *}$ \\
Other & 0.03 & $0.12^{* *}$ & 0.07 \\
\hline
\end{tabular}

Note. ${ }^{*} p<0.05,{ }^{* *} p<0.01,{ }^{* * *} p<0.001$.

\section{Discussion}

Our study conducted a broad examination of attitudes, beliefs, career outcome expectations, and career aspirations of women grouped in engineering disciplines that have above average, average, and below average female representation. Our discussion is broken down by theoretical constructs to allow for a broad review of the literature in each space and a discussion of how each construct may or may not be perceived as gendered. We hypothesized that women in the above average female representation group would display attitudes, beliefs, career outcome expectations, and career aspirations that were in line with feminine qualities, whereas the opposite would be true for women in the below average female representation group. We also hypothesize that women in engineering disciplines with average female representation would have a mixture of feminine and masculine attitudes and beliefs. For each subsection, we discuss how our results coincide with masculine or 
feminine social norms, based on prior literature, and the implications this has on engineering disciplines with below average and above average female representation.

\subsection{Future Time Perspective}

Future time perspective (FTP) is understood as the degree to which an individual's awareness of his/her future becomes integrated in the current way they set goals (Husman and Shell 2008). Our literature review found no indication that future time perspective is more or less salient for women than for men (gendered), nevertheless in our study, women in engineering disciplines with below average female representation reported significantly higher measures of perceptions of future ( $\beta=0.12, p<0.01$ ). Individuals with high measures of FTP are able to "perceive their behavior as more instrumental in achieving a broader range of both immediate and future goals" (McInerney 2004, p. 143). FTP has been found to relate to one's career decision-making self-efficacy (Walker and Tracey 2012), where self-efficacy is the belief in one's ability to achieve a desired goal or outcome (Bandura 1986). Thus, women in the below average female representation group may be more confident in their decision towards pursuing a career in in construction management engineering, electrical engineering, mechanical engineering, and aerospace engineering, and information technology irrespective of the lack of gender representation. Women in the above average female representation group were significantly higher in self-reported measures of instrumentality $(\beta=0.09, p<0.05)$, meaning they have positive perceptions of how their present tasks will become useful for their future goals (Nelson et al. 2017). Perhaps women in the above average female representation group have had more experiences connecting courses they've taken throughout high school (e.g., biology or chemistry) to their future careers. These results have implications for how women in these disciplines may persist and see their engineering education as relevant to their future goals.

\subsection{Psychological Personality Traits}

Only two psychological personality traits, from the Big Five list, were examined, agreeableness and conscientiousness. We found significant differences by interest in above average female-representation disciplines and below average female-representation engineering disciplines as hypothesized. Women in engineering disciplines with above average female representation were more likely to demonstrate the agreeableness personality trait $(\beta=0.18, p<0.001)$. Individuals high on agreeableness tend to act cooperatively and demonstrate unselfish mannerisms (VandenBos 2007; Graziano and Tobin 2009). Other characteristics of individuals high in this taxonomy include trustworthiness, collaboration, service oriented, conflict resolution, modesty, tendermindedness, and compliance (Pellegrino and Hilton 2012). Agreeableness has been positively associated with intrinsic motivation, which is associated with behaviors that are "done out of pleasure or for the sake of enjoyment" (Clark and Schroth 2010, p. 19). Studies have found that women tend to be higher on the agreeableness personality trait (Costa et al. 2001; Schmitt et al. 2008). Our findings indicate that women in the above average female representation group tend to endorse a personality trait that has been "correlated with femininity and not with masculinity" (Stake and Eisele 2010, p. 28). Perhaps women that are higher on agreeableness find that engineering fields with increased representation of women are compatible with their personality trait.

Conversely, women in engineering disciplines with above average female representation were less likely to demonstrate the conscientiousness personality trait $(\beta=-0.10, p<0.05)$, which implies an individual has a "tendency to be organized, responsible, and hardworking" (Pellegrino and Hilton 2012, p. 4). Gender differences in conscientiousness in various studies have been small and scattered, most concluding that virtually no differences between women and men exist (Costa et al. 2001; Stake and Eisele 2010). A study of Dutch engineers found that when compared to the general Dutch population, engineers were significantly more likely to be high on conscientiousness and less likely to be agreeable, however the authors recommended that "engineers should try to learn to be more agreeable in professional communication situations" (Van Der Molen et al. 2007, p. 499). We hypothesize that 
these results show differential factors for why women may be enrolling in engineering disciplines that they perceive to fit their own ways of interacting in the world and endorse more socially acceptable gender norms.

\subsection{Grit}

There has been continuous debate over achievement-focused measures (e.g., intelligence) and an increase interest in non-cognitive traits such as grit (Duckworth et al. 2007; Shechtman et al. 2013). Jaeger et al. (2010) posit that "in engineering, it is generally agreed that a baseline level of intellect, perception and ingenuity should be combined with a sufficient amount of perseverance, or grit, in order to succeed" (p. 1). While another study of first-year engineering students found that grit: persistence of effort predicted one- and two-year retention beyond, mathematics grades (Choi et al. 2017). Our results demonstrate that women in engineering disciplines with below average and above average female representation were more likely to have the intrapersonal characteristic of grit: persistence of effort. Our study shows that grit is present in students from certain engineering disciplines.

Grit has been connected to growth mindsets (Perkins-Gough 2013), where having a growth mindset is believing in the capacity to cultivate and improve one's abilities through continuous practice and effort (Dweck 2006). Our prior work has found that grit: persistence of effort is fostered through seeing oneself as the type of person that can do engineering (engineering identity) and feelings of belonging in the engineering major and classroom (Verdin et al. 2018). Conversely, there was a significantly negative association between women in the below average group and grit: consistency of interest. Having a negative association with grit: consistency of interest pertains to having a lack of maintained interest in ideas, topics, and goals over the long-term. Our finding calls into question whether women interested in the fields of construction management engineering, electrical engineering, mechanical engineering, and aerospace engineering, and information technology will remain interested in these fields or are more likely to lose interest and do so quickly.

\subsection{STEM Identities}

Results demonstrate the significant differences in STEM identities for women in fields that have a below average, average, and above average female representation. Women who rated being highly interested in the below average female representation group (construction management engineering, electrical engineering, mechanical engineering, and aerospace engineering, and information technology) were the only group to identify as engineers $(\beta=0.12, p<0.01)$. Subsequently, women in the below average female representation group were significantly more likely to be interested in engineering $(\beta=0.17, p<0.001)$ and believe they can understand and perform well in engineering $(\beta=0.11$, $p<0.05)$. Both being interested in engineering and believing one can perform well and understand concepts are critical components to seeing oneself as the type of person that can be an engineer (Godwin 2016; Godwin et al. 2016). The development of an engineering identity has important implications for academic and personal development (Stevens et al. 2008, 2005), retention (Walden and Foor 2008; Godwin and Potvin 2015), persistence, especially for women (Jones et al. 2013), and the future formation of a professional identity (Tonso 2006; Downey and Lucena 2003). Identifying as an engineer is not simply acquiring the necessary skills or knowledge, it also involves changing the "type of people we become and how someone understands him or herself in relation to a particular disciplinary practice" (e.g., mechanical engineering or aerospace engineering; (Stevens et al. 2008, p. 357)). The act of changing oneself to fit into the mold of engineering means that, especially for women, they must negotiate who they are and subscribe to engineering social norms that were created through and for a masculine image. Our results raise concerns about the type of engineering identity women in the below average female representation group are implicitly or explicitly ascribing to. Often, students are implicitly expected to choose between one aspect of who they are versus what it means to be an engineer. Matusovich et al. (2010) affirm this notion by drawing awareness to a disconnect between students' personal identities (aspects of individuals that make them unique) and engineering identity 
and emphasizing the need for these types of identities to be associated throughout the students engineering pathway. It is important to know who students are expected to be; enculturation into an engineering community of practice often requires that educators understand how students associate with, withdraw from, and/or negotiate the cultural norms of the community and their identities.

Lave and Wenger (1991) note that individuals seeking to develop their identity within their community of practice begin this journey through peripheral participation. From the "peripheral perspective, apprentices gradually assemble a general idea of what constitutes the practice" (Lave and Wenger 1991, p. 95) and for many first-year engineering students their peripheral participation to engineering are physics and mathematics courses in high school. Prior work has found that a physics identity significantly predicts choice of an engineering major, regardless of the engineering subfield (Godwin et al. 2016). Similarly, in a study that sought to understand how pre-college science experiences affected interest in engineering, the study found that students who were consistently interested in physics were more likely to remain interested in engineering throughout middle school, high school and the beginning of college (Cass et al. 2011). Our findings suggest that a physics identity is more salient among women in engineering disciplines with below average female representation $(\beta=0.17, p<0.001)$, whereas women in disciplines with above average female representation i.e., industrial engineering, chemical engineering, biological and agricultural engineering, biomedical engineering, environmental engineering, were less likely to identify as a physics person $(\beta=-0.09, p<0.05)$. These results are consistent with related work, from a sample of over 2000 male and female first-year engineering students, that found physics identity to be a positive, significant predictor of interest in aerospace engineering, mechanical engineering, electrical engineering and construction management engineering, and negatively related to biomedical engineering (Doyle 2017).

When we parsed out the constructs that make up a physics identity, women in engineering disciplines with below average female representation were significantly more likely to be interested in physics $(\beta=0.19, p<0.001)$, be recognized by instructors, family, and peers as the type of person that can do physics $(\beta=0.13, p<0.01)$, and have internalized beliefs about performing well and understanding physics concepts $(\beta=0.13, p<0.01$ ). In contrast, women in engineering disciplines with above average female representation were less likely to be recognized by others as someone that can be a physics person $(\beta=-0.09, p<0.05)$. The popular discourse of physics, as with engineering, is that it is incompatible with femininity and is an embodiment of a masculine activity (Gonsalves et al. 2016). Not surprising is our finding that women in disciplines that have below average female representation tend to identify more with physics, whereas women in above average female representation disciplines have a negative association with physics. Perhaps the identity construction of women interested in disciplines that are perceived as more masculine (per the below average female representation statistic) requires them to take on multiple forms of bids for recognition in the form of being more interested and believing in their performance/competence in both physics and engineering.

Lastly, upon examining women's identification with mathematics, our results reveal that women in engineering disciplines with average female representation (i.e., civil engineering, nuclear engineering, materials engineering, engineering physics, computer engineering, and other engineering) were more likely to identify as mathematics people, $(\beta=0.09, p<0.05)$, and subsequently have higher beliefs about their performance/competence in mathematics $(\beta=0.12, p<0.01)$. Godfrey and Parker (2010) note that mathematics is "essential as a key to access understanding and thinking like an engineer" (p. 8). Most interesting was the fact that only fields that had an average representation of women had statistically significant beliefs about performing well in mathematics and identifying with mathematics. This may indicate that mathematics could be a gateway subject for women, in fields that are more gender neutral. Conversely, identifying with physics may be an indication that physics is a gateway subject for women interested in fields that have a lower representation of women. 


\subsection{Career Outcome Expectations}

We found that women in the below average representation group were significantly higher than their peers in their desire to make money $(\beta=0.11, p<0.05)$, become well known $(\beta=0.11, p<0.05)$, supervise others $(\beta=0.13, p<0.01)$, and invent or design things $(\beta=0.09, p<0.05)$ in their careers. These outcomes are more aligned with the masculine personality and cognitive traits that Cejka and Eagly (1999) defined for masculine disciplines (see Table 1). This finding indicates that women who are more interested in engineering disciplines with below average female representation may have attitudes that conform more with the social norms in engineering that are seen as masculine. Other work in engineering education also demonstrated that certain outcome expectations like inventing new things (Orr et al. 2009), making money (Matusovich et al. 2010), and applying math and science (Godwin and Potvin 2014) were important for engineering career choice. In examining engineering career choice for all students, the attitudes reflected are largely those of men because they are overrepresented in engineering (Yoder 2015). Additionally, prior work found that the interaction effect between gender and inventing and designing things and applying math and science were negative (Godwin and Potvin 2014). This prior work indicates that women who valued these outcomes in their careers were less likely to choose engineering disciplines (Godwin and Potvin 2014). We find similar trends in our data overall, but for women interested in engineering disciplines with below average female representation, the career outcome expectations more closely match those of the dominant group in engineering, men.

In contrast, we found that women interested in engineering disciplines with above average female representation had significantly higher desire to help others $(\beta=0.22, p<0.001)$ and work with people $(\beta=0.11, p<0.05)$ than their peers. This result is consistent with prior work showing that female engineering students reported wanting to help people in their careers at a significantly higher rate than their male counterparts did (Orr et al. 2009).

The women in our study may not have had exposure to specific disciplinary cultures as they were surveyed in the first few weeks of their first year in a university. Our results indicate that outcome expectations attracting women towards a particular engineering discipline are not homogeneous; some women may be more motivated by one outcome expectation while others are more motivated by different expectations. Women with outcome expectations that are more closely aligned with the dominant outcome expectations that are culturally situated as masculine (e.g., making money, becoming well known, supervising others, and inventing or designing things) have higher interest in engineering disciplines with below average female representation. This result indicates that women with more masculine-normed attitudes may be more comfortable in choosing and participating in male-dominated career pathways. Conversely, women with more stereotypical female career outcome expectations were more likely to be interested in engineering disciplines with above average female representation. These results point to potential motivating factors and perceptions about engineering disciplines that have implications for how students are normed in engineering disciplines with more or less female representation and why particular trends in engineering enrollment occur. Additionally, the directionality of these outcomes cannot be inferred from our data. These women may have these particular goals, which attract them to particular disciplines, or their goals may be normed to the expectations of a highly male dominated field. However, we hypothesize that these may be particular individual differences that attract particular women to engineering disciplines with below average female representation versus above average female representation because the women in our study have not had the social exposure to particular disciplinary cultures yet. Instead, they are making decisions about their interests on engineering disciplines based on limited perceptions of what these engineers do and the larger social discourse on engineering in general (National Academy of Engineering NAE). 


\subsection{Career Aspirations}

While women remain in engineering majors at the same rate as men during their university years (Ohland et al. 2008), significantly fewer enter engineering industry positions than earn degrees in engineering (National Center for Education Statistics 2015). We examined women's self-reported career aspirations after graduation. Women in engineering disciplines with below average and average female representation were more likely than their above average representation peers to enter engineering industry (below average: $\beta=0.08, p<0.05$; average: $\beta=0.01, p<0.05$; above average: $\beta=-0.14, p<0.001$ ). This finding may explain some of the trends seen overall for women in engineering. The disciplines with above average female representation have higher numbers of women enrolled, but these women are much less likely to pursue engineering industry after graduation than their peers. Women in more male-dominated disciplines are more likely to choose an engineering industry as a career pathway. The overall trend of fewer women choosing engineering industry when engineering is treated as a monolith is more nuanced when examining women by different disciplines with more or less female representation. Women in male-dominated disciplines may receive messages that engineering industry is the more normative pathway for engineering graduates than women in other above average representation disciplines.

Women in engineering disciplines with below average $(\beta=0.12, p<0.01)$ and average $(\beta=0.10$, $p<0.05)$ female representation are more likely to want to start a company after graduation. Drawing on the broader gender literature, reviews of research in economics find robust evidence that women are more risk averse than men in most situations and particularly when making gambling or investment decisions (Blais and Weber 2001). Women perceive greater risk related to entrepreneurship (Brindley 2005; Masters and Meier 1988), which is characterized as an issue of economics, in that gender differences in risk aversion "will be reflected in all aspects of their decision making, including choice of profession" (Eckel and Grossman 2008, p. 1061). Our results show that these trends may be true of women in general, but female engineering students in more male-dominated disciplines are more aligned in their attitudes about entrepreneurship with men, based on prior literature, than with the female engineering counterparts in less male-dominated disciplines. Women who chose engineering disciplines that have more male-dominated contexts may be exposed to a different culture or risk taking and potential for entrepreneurship than their counterparts.

In contrast, women in engineering disciplines with above average female representation were more likely than their peers to enter medicine/health professions $(\beta=0.35, p<0.001)$ and non-profits/NGOs $(\beta=0.16, p<0.001)$. Indeed, women in engineering disciplines with below average $(\beta=-0.15, p<0.001)$ and average $(\beta=-0.08, p<0.05)$ female representation were less likely to enter medicine/health professions and were not significantly different on entering non-profits/NGOs. These career pathways are more in line with the prior discussion of career outcome expectations of helping others and working with people, which were significantly higher for women in disciplines with above average female representation. These career pathways also better align with career gender stereotypes that place importance on feminine personality characteristics (e.g., being nurturing and cooperative) for gender-aligned pathways (Cejka and Eagly 1999; Miller et al. 2015). As calls for branding engineering as a more people-oriented and helping profession have been made (National Academy of Engineering NAE; Su and Rounds 2015; Thaler 2005), these trends may not remain true for all women in engineering over time. Changing the messaging of engineering may continue to drive women, based on interests, into engineering disciplines that were previously seen as uninteresting.

Women in engineering disciplines with below average $(\beta=0.11, p<0.05)$ and above average $(\beta=0.13, p<0.01)$ female representation were more likely than their peers to want to enter law. Women have had significant gains in representation in law over the past few decades (Hill et al. 2010). The types of law that these women are interested in practicing may or may not be different from their particular career interests (Su and Rounds 2015). However, it is not surprising to find that women across engineering disciplines are interested in a career pathway that has seen significant growth in female representation over time (unlike other career pathways listed). 
We also found significant differences for women in average female representation disciplines from their peers for interests in K-12 education $(\beta=0.10, p<0.05)$ and other careers $(\beta=0.12, p<0.01)$. These differences may be due to the particular engineering disciplines categorized as average female representation (i.e., civil engineering, nuclear engineering, materials engineering, engineering physics, computer engineering, and other engineering). These engineering disciplines have the least traditional career pathways based on the disciplinary topics and diversity of foci (Godfrey and Parker 2010). Interestingly, we also found no significant differences in female engineering students' desire to enter academia/higher education or government/policy.

\subsection{Overall Findings}

In this work, we hypothesized that women in the above average female representation group would display attitudes, beliefs, career outcome expectations, and career aspirations that were in line with feminine qualities, whereas the opposite would be true for women in the below-average female representation group. We did find that women who were most interested in engineering disciplines with above average female representation had attitudes and career goals more aligned with feminine traits including higher agreeableness, lower physics identities, higher interest in helping others and working with people in their careers, lower interest in entering engineering industry and higher interest in law, medicine, and non-profit organizations as career pathways than their female peers. Women most interested in engineering disciplines with below average female representation showed stronger masculine attributes including higher engineering and physics identities, stronger persistence of effort, more desire to make money and supervise others, and a stronger desire to enter engineering industry or start a company than their female peers. Women most interested in the average female representation engineering disciplines had higher mathematics identities, interest in entering engineering industry and other career pathways than their female peers. Together, these results point to particular attitudes and beliefs that may differentially attract women to engineering as a male-dominated discipline overall and may have some effect in engineering disciplinary choices in the university setting.

\section{Limitations and Future Work}

This study utilized a cross-sectional survey design. This data represents one specific point in time, and based on this data, we are unable to draw causal inferences or conclusions. We hypothesized that women enter engineering with different attitudes that may make them more or less inclined to choose particular above or below average female representation engineering disciplines. However, we have no way to determine the causality of such hypotheses with the data used in this study, nor can we account for the many other factors that affect engineering disciplinary choices.

Future work is needed to understand how women's attitudes across engineering disciplines change over time. For example, additional research is needed to understand how students, specifically women, perceive disciplinary cultures in engineering once they have entered their chosen majors. To date, only one study has looked at how the climate of an engineering discipline (industrial engineering) attracts more women.

Our study did not focus on students living with intersecting social identities (e.g., race/ethnicity, first-generation college student, or domestic/international status); we only focused on gender. Future work should focus on how these varying social identities differentially affect women's attitudes and pathways in engineering as a male-dominated discipline.

Because our study aimed to investigate differences in women's attitudes as they enter engineering degree programs, the male population was not included in our analyses. The limitations to this approach include the inability to make comparisons across gender. Whereas this study intentionally focused on understanding women across engineering disciplines, there is also merit in understanding how men vary across engineering disciplines and the comparison between genders. Future work will seek to understand how both men and women in different engineering disciplines vary in terms of attitudes, beliefs, and motivation. 


\section{Conclusions}

The results of this study indicate the women who are interested in engineering disciplines with different representations of women (i.e., are more or less male-dominated) have significantly different attitudes and beliefs, career goals, and career plans. These findings have implications for how women do or do not conform to the masculine social norms of engineering overall and why women may be enrolling in engineering disciplines at different rates. While this work did not examine the cultural factors that may influence women in their engineering disciplines, it is the first systematic examination of women's attitudes across engineering disciplines and provides information about the perceptions that women may have and attitudes that they bring with them into particular engineering pathways. The results of this study provide a starting point to understand how women may be recruited into engineering disciplines with below average female representation and how they can be retained in disciplines where there is a higher representation of women.

Supplementary Materials: The following are available online at www.mdpi.com/2076-0760/7/3/44/s1, The mean, standard deviation, and correlation matrix can be found online for all the variables used in this analysis.

Acknowledgments: This work was supported by the National Science Foundation through award numbers EEC-1428523 and EEC-1428689 and the National Science Foundation Graduate Research Fellowship grant number DGE-1333468. The opinions expressed are those of the author and do not necessarily represent those of the NSF. The authors wish to thank the participants of the surveys and the Intersectionality of Non-normative Identities in the Cultures of Engineering (InIce) research groups including Jacqueline Doyle, Hank Boone, and Monique Ross, for their support in collecting this data.

Author Contributions: Lisa Benson, Geoff Potvin, Adam Kirn and Allison Godwin were awarded funding to collect the data; Dina Verdín was awarded the Graduate Research Fellowship; Dina Verdín and Allison Godwin conceived and designed the analysis; Dina Verdín conducted the analysis; Dina Verdín and Allison Godwin wrote the paper; Adam Kirn, Lisa Benson and Geoff Potvin provided edits and feedback to the manuscript.

Conflicts of Interest: The authors declare no conflict of interest. The founding sponsors had no role in the design of the study; in the collection, analyses, or interpretation of data; in the writing of the manuscript, and in the decision to publish the results.

\section{References}

Akpanudo, Usenime M., James L. Huff, and Allison Godwin. 2017. Hidden in Plain Sight: Masculine Social Norms in Engineering Education. Paper presented at the Frontiers in Education Conference (FIE), Indianapolis, IN, USA, October 18-21. [CrossRef]

Bandura, Albert. 1986. Social Foundations of Thought and Action: A Social Cognitive Theory. Englewood Cliffs: Prentice-Hall, Inc.

Ben-Shem, Idit, and Tamara E. Avi-Itzhak. 1991. On Work Values and Career Choice in Freshmen Students: The Case of Helping vs. Other Professions. Journal of Vocational Behavior 39: 369-79. [CrossRef]

Benson, L., G. Potvin, A. Kirn, A. Godwin, J. Doyle, J. A. Rohde, D. Verdín, and H. Boone. 2017. Board \# 9 : Characterizing Student Identities in Engineering: Attitudinal Profiles of Engineering Majors. Paper presented at American Society for Engineering Education Annual Conference, Columbus, OH, USA, June 24-28. Available online: https: / / peer.asee.org/27950 (accessed on 2 June 2017).

Bix, Amy Sue. 2004. From 'Engineeresses' to ‘Girl Engineers' to 'Good Engineers': A History of Women's U.S. Engineering Education. NWSA Journal 16: 27-49. [CrossRef]

Blais, Ann-Renée, and Elke U. Weber. 2001. Domain-Specificity and Gender Differences in Decision Making. Risk Decision and Policy 6: 47-69. [CrossRef]

Brawner, Catherine E., Michelle M. Camacho, Susan M. Lord, Russell A. Long, and Matthew W. Ohland. 2012. Women in Industrial Engineering: Stereotypes, Persistence, and Perspectives. Journal of Engineering Education 101: 288-318. [CrossRef]

Brickhouse, Nancy W., Patricia Lowery, and Katherine Schultz. 2000. What Kind of Girl Does Science? The Construction of School Science Identities. Journal of Research in Science Teaching 37: 441-58. [CrossRef]

Brindley, Clare. 2005. Barriers to Women Achieving Their Entrepreneurial Potential. International Journal of Entrepreneurial Behavior \& Research 11: 144-61. [CrossRef] 
Bureau of Labor Statistics. 2018. U.S. Department of Labor, The Economics Daily, 39 Percent of Managers in 2015 Were Women. Available online: https:/ / www.bls.gov/opub/ted/2016/39-percent-of-managers-in-2015were-women.htm (accessed on 20 February 2018).

Camacho, Michelle M., Susan M. Lord, Catherine E. Brawner, and Matthew W. Ohland. 2010. Climate in Undergraduate Engineering Education from 1995 to 2009. Paper presented at Frontiers in Education Conference, Washington, DC, USA, October 27-30, pp. 1-6.

Carlone, Heidi, and Angela Johnson. 2007. Understanding the Science Experience of Successful Women of Color: Science Identity as an Analytic Lens. Journal of Research in Science Teaching 44: 1187-218. [CrossRef]

Cass, Cheryl A. P., Zahra Hazari, Philip M. Sadler, and Gerhard Sonnert. 2011. Engineering Persisters and Non-Persisters: Understanding Inflow and Outflow Trends between Middle School and College. Paper presented at American Society for Engineering Education (ASEE) Annual International Conference, Vancouver, BC, USA, June 26-29.

Cejka, Mary Ann, and Alice H. Eagly. 1999. Gender-Stereotypic Images of Occupations Correspond to the Sex Segregation of Employment. Personality and Social Psychology Bulletin 25: 413-23. [CrossRef]

Choi, Dong San, Beth Myers, and Michael C. Loui. 2017. Grit and Two-Year Engineering Retention. Paper presented at Frontiers in Education Conference, Indianapolis, IN, USA, October 18-21, pp. 3-5.

Cialdini, Robert B., and Melanie R. Trost. 1998. Social Influence: Social Norms, Conformity and Compliance. In The Handbook of Social Psychology. Edited by Daniel T. Gilvert, Susan T. Fiske and Gardner Lindzy. Boston: MaGraw Hill, vol. 2, pp. 151-92. [CrossRef]

Clark, M. H., and Christopher A. Schroth. 2010. Examining Relationships between Academic Motivation and Personality among College Students. Learning and Individual Differences 20: 19-24. [CrossRef]

Collinson, David L. 1998. 'Engineering Humour': Masculinity, Joking and Conflict in Shop-Floor Relations. Organization Studies 9: 181-99. [CrossRef]

Costa, Paul, Jr., Antonio Terracciano, and Robert R. McCrae. 2001. Gender Differences in Personality Traits across Cultures: Robust and Surprising Findings. Journal of Personality and Social Psychology 81: 322-31. [CrossRef] [PubMed]

Cribbs, Jennifer D., Zahra Hazari, Gerhard Sonnert, and Philip M. Sadler. 2015. Establishing an Explanatory Model for Mathematics Identity. Child Development 86: 1048-62. [CrossRef] [PubMed]

Curran, Patrick J., Stephen G. West, and John F. Finch. 1996. The Robustness of Test Statistics to Nonnormality and Specification Error in Confirmatory Factor Analysis. Psychological Methods 1: 16-29. [CrossRef]

de Pillis, Emmeline, and Lisette de Pillis. 2008. Are Engineering Schools Masculine and Authoritarian? The Mission Statements Say Yes. Journal of Diversity in Higher Education 1: 33-44. [CrossRef]

Downey, Gary, and Juan Lucena. 2003. When Students Resist: Ethnography of a Senior Design Experience in Engineering Education. International Journal of Engineering Education 19: 168-76.

Doyle, Jacqueline. 2017. Describing and Mapping the Interactions between Students Affective Factors Related to Persistence in Science, Physics, and Engineering. Miami: Florida International University.

Du, Xiang-Yun. 2006. Gendered Practices of Constructing an Engineering Identity in a Problem-Based Learning Environment. European Journal of Engineering Education 31: 35-42. [CrossRef]

Duckworth, Angela Lee, and Patrick D. Quinn. 2009. Development and Validation of the Short Grit Scale (Grit-S). Journal of Personality Assessment 91: 166-74. [CrossRef] [PubMed]

Duckworth, Angela L., Christopher Peterson, Michael D. Matthews, and Dennis R. Kelly. 2007. Grit: Perseverance and Passion for Long-Term Goals. Journal of Personality and Social Psychology 92: 1087-101. [CrossRef] [PubMed]

Dweck, Carol S. 2006. Mindset: The New Psychology of Success. Munich: Random House Incorporated.

Eckel, Catherine C., and Philip J. Grossman. 2008. Men, Women and Risk Aversion: Experimental Evidence. In Handbook of Experimental Economics Results. New York: Elsevier, pp. 1061-73.

Elliot, Andrew J., and Holly A. McGregor. 2001. A 2 X 2 Achievement Goal Framework. Journal of Personality and Social Psychology. [CrossRef]

Faulkner, Wendy. 2000. Dualisms, Hierarchies and Gender in Engineering. Social Studies of Science 30: 759-92. [CrossRef]

Faulkner, Wendy. 2007. Nuts and Bolts and People' Gender-Troubled Engineering Identities. Social Studies of Science 37: 331-56. [CrossRef] 
Faulkner, Wendy. 2009. Doing Gender in Engineering Workplace Cultures. I. Observations from the Field. Engineering Studies 1: 3-18. [CrossRef]

Faulkner, Wendy. 2013. Doing Gender in Engineering Workplace Cultures. II. Gender In/authenticity and the in/visibility Paradox. Engineering Studies 1: 169-89. [CrossRef]

Foor, Cindy E., and Susan E. Walden. 2009. "Imaginary Engineering" or "Re-imagined Engineering": Negotiating Gendered Identities in the Borderland of a College of Engineering. NWSA Journal 21: 41-64.

Frehill, Lisa M. 2004. The Gendered Construction of the Engineering Profession in the United States, 1893-1920. Men and Masculinities 6: 383-403. [CrossRef]

Gee, James Paul. 2001. Identity as an Analytic Lens for Research in Education. Review of Research in Education 25: 99-126. [CrossRef]

Geisinger, Brandi N., and D. Raj Raman. 2013. Why They Leave: Understanding Student Attrition from Engineering Majors. International Journal of Engineering Education 29: 914-25.

Godfrey, Elizabeth. 2007. Cultures within Cultures: Welcoming or Unwelcoming for Women? Paper presented at 2007 Annual Conference \& Exposition, Honolulu, HI, USA, June 24-27.

Godfrey, Elizabeth, and Lesley Parker. 2010. Mapping the Cultural Landscape in Engineering Education. Journal of Engineering Education 99: 5-22. [CrossRef]

Godwin, Allison. 2016. The Development of a Measure of Engineering Identity. Paper presented at 2016 ASEE Annual Conference \& Exposition, New Orleans, LA, USA, June 26-28. [CrossRef]

Godwin, Allison, and Geoff Potvin. 2013. Chemical Engineering Students: A Distinct Group among Engineers. Chemical Engineering Education 47: 145-53.

Godwin, Allison, and Geoff Potvin. 2014. Modeling Engineering Choice Using Student Attitudes and Self-Beliefs. Paper presented at the Annual Meeting of the American Educational Research Association, Philadelphia, PA, USA, April 7. AERA Online Paper Repository.

Godwin, Allison, and Geoff Potvin. 2015. Fostering Female Belongingness in Engineering through the Lens of Critical Engineering Agency. International Journal of Engineering Education 31: 938-52.

Godwin, Allison, Geoff Potvin, Zahra Hazari, and Robynne Lock. 2013. Understanding Engineering Identity through Structural Equation Modeling. Paper presented at Frontiers in Education Conference, FIE, Oklahoma City, OK, USA, October 23-26, pp. 50-56. [CrossRef]

Godwin, Allison, Geoff Potvin, Zahra Hazari, and Robynne Lock. 2016. Identity, Critical Agency, and Engineering: An Affective Model for Predicting Engineering as a Career Choice. Journal of Engineering Education, 105. [CrossRef]

Godwin, Allison, Dina Verdín, Adam Kirn, and Satterfield. 2018. The Intersection of Gender and Race: Exploring Chemical Engineering Students' Attitudes. Chemical Engineering Education, 52.

Goldberg, Lewis R. 1992. The Development of Markers for the Big-Five Factor Structure. Psychological Assessment 4: 26-42. [CrossRef]

Gonsalves, Allison J., Anna Danielsson, and Helena Pettersson. 2016. Masculinities and Experimental Practices in Physics: The View from Three Case Studies. Physical Review Physics Education Research 12: 1-15. [CrossRef]

Graziano, William G., and Renee M. Tobin. 2009. Agreeableness. In Handbook of Individual Differences in Social Behavior. Edited by Mark R. Leary and Rick H. Hoyle. New York: Guilford Press, pp. 46-61.

Hartman, Harriet, and Moshe Hartman. 2009. Do Gender Differences in Undergraduate Engineering Orientations Persist When Major Is Controlled? International Journal of Gender, Science and Technology 1: 61-82.

Hazari, Zahra, Gerhard Sonnert, Philip M. Sadler, and Marie-Claire Shanahan. 2010. Connecting High School Physics Experiences, Outcome Expectations, Physics Identity, and Physics Career Choice: A Gender Study. Journal of Research in Science Teaching 47: 978-1003. [CrossRef]

Henwood, Flis. 1996. WISE Choices? Understanding Occupational Decision-Making in a Climate of Equal Opportunities for Women in Science and Technology. Gender and Education 8: 199-214. [CrossRef]

Hill, Catherine, Christianne Corbett, and Andresse St Rose. 2010. Why So Few? Women in Science, Technology, Engineering, and Mathematics. Washington: American Association of University Women.

Husman, Jenefer, and Wily Lens. 1999. The Role of the Future in Student Motivation. Educational Psychologist 34: 113-25. [CrossRef]

Husman, Jenefer, and Duane F. Shell. 2008. Beliefs and Perceptions about the Future: A Measurement of Future Time Perspective. Learning and Individual Differences 18: 166-75. [CrossRef] 
Izraeli, Dafna, Moshe Krausz, and Rivka Garber. 1979. Student Self-Selection for Specializations in Engineering. Journal of Vocational Behavior 15: 107-17. [CrossRef]

Jaeger, Beverly, Susan Freeman, Richard Whalen, and Rebecca Payne. 2010. Successful Students: Smart or Tough? Paper presented at 2010 Annual Conference \& Exposition, Louisville, KU, USA, June 20-23.

Johnson, Angela, Jaweer Brown, Heidi Carlone, and Azita K. Cuevas. 2011. Authoring Identity the Treacherous Terrain of Science: A Multiracial Feminist Examination of the Journeys of Three Women of Color in Science. Journal of Research in Science Teaching 48: 339-66. [CrossRef]

Jones, Brett D., Chloe Ruff, and Marie C. Paretti. 2013. The impact of engineering identification and stereotypes on undergraduate women's achievement and persistence in engineering. Social Psychology of Education 16: 471-93. [CrossRef]

Jorgenson, Jane. 2002. Engineering Selves Negotiating Gender and Identity in Technical Work. Management Communication Quarterly 15: 350-80. [CrossRef]

Kirn, Adam, and Lisa Benson. 2018. Engineering Students' Perceptions of Problem Solving and their Future. Journal of Engineering Education, 107. [CrossRef]

Kirn, Adam, Allison Godwin, Lisa Benson, Geoff Potvin, Jacqueline Doyle, Dina Verdín, and Hank Boone. 2016. Intersectionality of Non-Normative Identities in the Cultures of Engineering (InIce). Paper presented at American Society for Engineering Education Annual Conference, New Orleans, LA, USA, June 26-28. [CrossRef]

Komarraju, Meera, Steven J. Karau, and Ronald R. Schmeck. 2009. Role of the Big Five Personality Traits in Predicting College Students' Academic Motivation and Achievement. Learning and Individual Differences 19: 47-52. [CrossRef]

Komarraju, Meera, Steven J. Karau, Ronald R. Schmeck, and Alen Avdic. 2011. The Big Five Personality Traits, Learning Styles, and Academic Achievement. Personality and Individual Differences 51: 472-77. [CrossRef]

Lave, Jane. 1992. Learning as Participation in Communities of Practice. San Francisco: American Educational Research Association.

Lave, Jean, and Etienne Wenger. 1991. Situated Learning: Legitimate Peripheral Participation. Cambridge: Cambridge University Press.

Lent, Robert W., Steven D. Brown, and Gail Hackett. 1994. Towards a Unifying Social Cognitive Theory of Career and Academic Interest, Choice, and Performance. Journal of Vocational Behavior 45: 79-122. [CrossRef]

Lent, Robert W., Steven D. Brown, and Gail Hackett. 2000. Contextual Supports and Barriers to Career Choice: A Social Cognitive Analysis. Journal of Counseling Psychology 47: 36-49. [CrossRef]

Lent, Robert W., Steven D. Brown, and Gail Hackett. 2002. Social Cognitive Career Theory. In Career Choice and Development. Edited by Duane Brown and Associates. San Francisco: Jossey-Bass, pp. 255-311.

Lent, Robert W., Steven D. Brown, Janet Schmidt, Bradley Brenner, Heather Lyons, and Dana Treistman. 2003. Relation of Contextual Supports and Barriers to Choice Behavior in Engineering Majors: Test of Alternative Social Cognitive Models. Journal of Counseling Psychology 50: 458-65. [CrossRef]

Lord, Susan M., Richard A. Layton, and Matthew W. Ohland. 2011. Trajectories of Electrical Engineering and Computer Engineering Students by Race and Gender. IEEE Transactions on Education 54: 610-18. [CrossRef]

Masters, Robert, and Robert Meier. 1988. Sex Differences and Risk-Taking Propensity of Entrepreneurs. Journal of Small Business Management 26: 31.

Matusovich, Holly M., Ruth A. Streveler, and Ronald L. Miller. 2010. Why Do Students Choose Engineering? A Qualitative, Longitudinal Investigation of Students' Motivational Values. Journal of Engineering Education 99: 289-303. [CrossRef]

McCabe, Kira O., Nico W. Van Yperen, Andrew J. Elliot, and Marc Verbraak. 2013. Big Five Personality Profiles of Context-Specific Achievement Goals. Journal of Research in Personality 47: 698-707. [CrossRef]

McCrae, Robert R., and Paul T. Costa. 1997. Personality Trait Structure as a Human Universal. American Psychologist 52: 509-16. [CrossRef] [PubMed]

McInerney, Dennis M. 2004. A Discussion of Future Time Perspective. Educational Psychology Review 16: 141-51. [CrossRef]

Menard, Scott. 1995. Applied Logistic Regression Analysis: Sage University Series on Quantitative Applications in the Social Sciences. Thousand Oaks: Sage. 
Miller, David I., Alice H. Eagly, and Marcia C. Linn. 2015. Women's Representation in Science Predicts National Gender-Science Stereotypes: Evidence from 66 Nations. Journal of Educational Psychology 107: 631-44. [CrossRef]

Muthen, Bengt, and David Kaplan. 1992. A Comparison of Some Methodologies for the Factor-Analysis of Non-Normal Likert Variables. British Journal of Mathematical \& Statistical Psychology 45: 19-30.

National Academies Committee on Science, Engineering and Public Policy. 2007. Beyond Bias and Barriers: Fulfilling the Potential of Women in Academic Science and Engineering. Washington: National Academies Press.

National Academy of Engineering (NAE). 2008. Changing the Conversation: Messages for Improving Public Understanding of Engineering Committee. Washington: NAE.

National Center for Education Statistics. 2015. Women, Minorities, and Persons with Disabilities in Science and Engineering. Available online: http:/ / www.nsf.gov/statistics/wmpd/ (accessed on 2 June 2017).

Nelson, Katherine G., Jenefer Husman, Katherine C. Cheng, and Judith M. Harackiewicz. 2017. 'I Want to Be an Engineer, Why Should I Study Biology?'-Using Future Time Perspective to Understand Students' Beliefs about Foundational Courses. Paper presented at 2017 ASEE Annual Conference \& Exposition, Columbus, OH, USA, June 24-28; Available online: https:/ / peer.asee.org/27428 (accessed on 20 November 2017).

Ohland, Matthew W., Sheri D. Sheppard, Gary Lichtenstein, Ozgur Eris, Debbie Chachra, and Richard Layton. 2008. Persistence, Engagement, and Migration in Engineering Programs. Journal of Engineering Education 97: 259-78. [CrossRef]

Orr, Marisa, Zahra Hazari, Philip M. Sadler, and Gerhard Sonnert. 2009. Career Motivations of Freshman Engineering and Non-Engineering Students: A Gender Study. Paper presented at 2009 Annual Conference \& Exposition, Austin, TX, USA, June 14-17; Available online: https: / / peer.asee.org / 4872 (accessed on 20 October 2017).

Pellegrino, James W., and Margaret L. Hilton. 2012. Education for Life and Work: Developing Transferable Knowledge and Skills in the 21 St Century. Washington: National Academies Press.

Perkins, H. Wesley, and Alan D. Berkowitz. 1986. Perceiving the Community Norms of Alcohol Use among Students: Some Research Implications for Campus Alcohol Education Programming. International Journal of the Addictions 21: 961-76. [CrossRef] [PubMed]

Perkins-Gough, Deborah. 2013. The Significance of Grit: A Conversation with Angela Lee Duckworth. Educational Leadership 71: 14-20.

Phipps, Alison. 2002. Engineering Women: The 'Gendering' of Professional Identities. International Journal of Engineering Education 18: 409-14.

Potvin, Geoff, and Zahra Hazari. 2013. The Development and Measurement of Identity across the Physical Sciences. Paper presented at Physics Education Research Conference, Portland, OR, USA, July 17-18, pp. 281-84. [CrossRef]

Potvin, Geoff, Zahra Hazari, Leidy Klotz, Allison Godwin, Robynne Lock, Jennifer Cribbs, and Nicole Barclay. 2013. Disciplinary Differences in Engineering Students' Aspirations and Self-Perceptions. Paper present at the ASEE 2013 Annual Conference \& Exposition, Atlanta, GA, USA, June 23-26, pp. 1-11. Available online: https:/ / peer.asee.org/19452 (accessed on 2 June 2017).

President's Council of Advisors on Science and Technology. 2012. Engage to Excel: Producing One Million Additional College Graduates with Degrees in Science, Technology, Engineering, and Mathematics. Available online: http:/ / www.whitehouse.gov/sites/default/files/microsites/ostp/pcast-engage-to-excel-v11.pdf (accessed on 10 December 2017).

R Core Team. 2017. R: A Language and Environment for Statistical Computing. Vienna: R Foundation for Statistical Computing.

Roberts, Brent W., Joshua Jackson, Jennifer V. Fayard, Grant Edmonds, and Jenna Meints. 2009. Conscientiousness. In Handbook of Individual Differences in Social Behavior. Edited by Mark R. Leary and Rick H. Hoyle. New York: Guilford Press, pp. 369-81.

Ross, Scott R., M. Karega Rausch, and Kelli E. Canada. 2003. Competition and Cooperation in the Five-Factor Model: Individual Differences in Achievement Orientation. The Journal of Psychology 137: 323-37. [CrossRef] [PubMed]

SaGE Survey. 2011. SaGE: Sustainability and Gender in Engineering (Survey). Clemson: Clemson University. Available online: https:/ / engineering.purdue.edu/ENE/Research/SaGE_survey_Godwin_2014 (accessed on 10 December 2017). 
Schmitt, David P., Anu Realo, Martin Voracek, and Jüri Allik. 2008. Why Cannot a Man Be More like a Woman? Sex Differences in Big Five Personality Traits across 55 Cultures. Journal of Personality and Social Psychology 94: 168. [CrossRef] [PubMed]

Seymour, Elaine, and Nancy M. Hewitt. 1997. Talking about Leaving: Why Undergraduates Leave the Sciences. Boulder: Westview.

Shechtman, Nicole, Angela H. DeBarger, Carolyn Dornsife, Soren Rosier, and Louise Yarnall. 2013. Promoting Grit, Tenacity, and Perseverance: Critical Factors for Success in the 21st Century; Washington: US Department of Education, Department of Educational Technology. [CrossRef]

Shell, Duane F., and Jenefer Husman. 2008. Control, Motivation, Affect, and Strategic Self-Regulation in the College Classroom: A Multidimensional Phenomenon. Journal of Educational Psychology 100: 443-59. [CrossRef]

Slaton, Amy E. 2015. Meritocracy, Technocracy, Democracy: Understandings of Racial and Gender Equity in American Engineering Education. In International Perspectives on Engineering Education. Berlin: Springer, pp. 171-89.

Smith, Jessi L., Karyn L. Lewis, Lauren Hawthorne, and Sara D. Hodges. 2012. When Trying Hard Isn't Natural: Women's Belonging With and Motivation for Male-Dominated STEM Fields as a Function of Effort Expenditure Concerns. Personality and Social Psychology Bulletin 39: 131-43. [CrossRef] [PubMed]

Snyder, Thomas D., Cristobal de Brey, and Sally A. Dillow. 2016. Digest of Education Statistics, 2014. Available online: http:/ / nces.ed.gov/pubsearch/pubsinfo.asp?pubid=2016006 (accessed on 10 December 2017).

Sorić, Izabela, Zvjezdan Penezić, and Irena Burić. 2017. The Big Five Personality Traits, Goal Orientations, and Academic Achievement. Learning and Individual Differences 54: 126-34. [CrossRef]

Stake, Jayne E., and Heather Eisele. 2010. Gender and Personality. In Handbook of Gender Research in Psychology. Edited by Joan. C. Chrisler and Donald. R. McCreary. Berlin: Springer, pp. 19-40.

Stevens, Reed, Kevin O'Connor, and Lari Garrison. 2005. Engineering Student Identities in the Navigation of the Undergraduate Curriculum. Paper presented at 2005 Annual Conference, Oregon, Portland, June 12-15. Available online: https:/ / peer.asee.org/14754 (accessed on 21 October 2017).

Stevens, Reed, Kevin O'Connor, Lari Garrison, Andrew Jocuns, and Daniel M. Amo. 2008. Becoming an Engineer: Toward a Three Dimensional View of Engineering Learning. Journal of Engineering Education 97: 355-68. [CrossRef]

$\mathrm{Su}$, Rong, and James Rounds. 2015. All STEM Fields Are Not Created Equal: People and Things Interests Explain Gender Disparities across STEM Fields. Frontiers in Psychology 6: 189. [CrossRef] [PubMed]

Tavakol, Mohsen, and Reg Dennick. 2011. Making Sense of Cronbach's Alpha. International Journal of Medical Education 2: 53-55. [CrossRef] [PubMed]

Thaler, Anita. 2005. To Succeed or Not Succeed, That Is the Woman Engineer's Question. Paper present at the International Conference: "Creating Cultures of Success for Women Engineers" Schloss Retzhof, Leibnitz/Graz, Austria, October 6-8.

Tonso, Karen L. 2006. Student Engineers and Engineer Identity: Campus Engineer Identities as Figured World. Cultural Studies of Science Education 1: 273-307. [CrossRef]

Tonso, Karen L. 2006. Teams That Work: Campus Culture, Engineer Identity, and Social Interactions. Journal of Engineering Education 95: 25-37. [CrossRef]

Tonso, Karen L. 2007. On the Outskirts of Engineering: Learning Identity, Gender, and Power via Engineering Practice. Rotterdam: Sense.

Trapmann, Sabrina, Benedikt Hell, Jan-Oliver W. Hirn, and Heinz Schuler. 2007. Meta-Analysis of the Relationship between the Big Five and Academic Success at University. Zeitschrift Für Psychologie/Journal of Psychology 215: 132-51. [CrossRef]

Van Der Molen, Henk T., Henk G. Schmidt, and Gerard Kruisman. 2007. Personality Characteristics of Engineers. European Journal of Engineering Education 32: 495-501. [CrossRef]

VandenBos, Gary R. 2007. APA Dictionary of Psychology. Washington: American Psychological Association.

Verdín, Dina, and Allison Godwin. 2018. First-Generation College Students Identifying as Future Engineers. Paper presented at the Annual Meeting of the American Educational Research Association, New York, NY, USA, April 12-17. AERA Online Paper Repository. 
Verdín, Dina, Allison Godwin, Adam Kirn, Lisa Benson, and Geoff Potvin. 2018. Understanding How Engineering Identity and Belongingness Predict Grit for First-Generation College Students. Paper presented at The Collaboration Network for Engineering and Computing Diversity Conference, Crystal City, VA, USA, April 29-May 2.

Walden, Susan E., and Cindy Foor. 2008. 'What's to Keep You from Dropping Out?' Student Immigration into and within Engineering. Journal of Engineering Education 97: 191-205. [CrossRef]

Walker, Terrance L., and Terence J. G. Tracey. 2012. The Role of Future Time Perspective in Career Decision-Making. Journal of Vocational Behavior 81: 150-58. [CrossRef]

Yoder, Brian L. 2015. Engineering by the Numbers. Washington, DC, USA. Available online: https://www. asee.org/papers-and-publications / publications/college-profiles/15EngineeringbytheNumbersPart1.pdf (accessed on 2 June 2017).

(C) 2018 by the authors. Licensee MDPI, Basel, Switzerland. This article is an open access article distributed under the terms and conditions of the Creative Commons Attribution (CC BY) license (http:/ / creativecommons.org/licenses/by/4.0/). 